\title{
Experiences of nursing students in caring for patients with behaviors suggestive of low health literacy: a qualitative analysis
}

\author{
Carol Shieh, Anne E. Belcher, Barbara Habermann \\ School of Nursing, Indiana University, Indianapolis, Indiana
}

Correspondence: Carol Shieh. Address: 1111 Middle Drive, Indianapolis, IN 46202. Telephone: 317-278-1575. Email: wshieh@iupui.edu.

Received: May 26, 2012

Accepted: June 21, $2012 \quad$ Published: February 1, 2013

DOI : $10.5430 /$ jnep.v3n2p75

URL: http://dx.doi.org/10.5430/jnep.v3n2p75

\begin{abstract}
Background: Health literacy is the ability to obtain, process, and understand health information in order to take appropriate health actions. Low health literacy is associated with poor health knowledge and self-management of chronic disease, inadequate utilization of preventive services, and increased hospital admissions. The American Association of Colleges of Nursing recommends that nursing schools incorporate health literacy into curricula. Little, however, has been reported about what nursing students have learned and done about health literacy in clinical. This study explored undergraduate nursing students' experiences in caring for patients with low health literacy.
\end{abstract}

Methods: A qualitative content analysis method was used to analyze 59 narratives written by undergraduate nursing students.

Results: Three themes were uncovered: sensing low health literacy by behavioral cues, promoting health literacy with multiple strategies, and closing the health information loop with positive and negative feelings. Noncompliance, knowledge deficits, anxiety/concerns, and language barriers were behavioral cues indicating low health literacy, and these cues triggered the students' information support actions. Students promoted patient understanding and utilization of information by using many interventions: simplifying information, reinforcing information, giving written information, and demonstration/teach-back. Many students felt good about being able to help increase knowledge and self-care skills of their patients. Some were frustrated because they were unable to promote lifestyle modifications of the patients with complicated chronic diseases. Students, however, did not employ standardized tools to assess the health literacy of the patient or the patient's knowledge of specific diseases, nor did they assess readability of patient education materials or provide patient empowerment interventions to encourage active information-seeking and participation in self-care.

Conclusions: Nursing students could identify behavioral cues suggestive of low health literacy and provide solutions to increase the patient's health literacy. To enhance student practice, nursing curricula, however, can integrate relevant health literacy assessment tools and empowerment interventions.

\section{Key words}

Health literacy, Nursing education, Curricular development, Clinical teaching 


\section{Introduction}

The U.S. Department of Health and Human Services defines health literacy as "the capacity to obtain, process, and understand basic health information and services needed to make appropriate health decisions" ${ }^{[1]}$. In other words, health literacy is about making sense of health information and using it to facilitate health actions. About $36 \%$ of U.S. adults have low health literacy and elderly, minorities, non-English speaking persons, and individuals with less education or lower socio-economic status are especially at risk for low health literacy ${ }^{[2]}$. Health literacy has become an emerging priority in U.S. healthcare practice because low health literacy can lead to increased disease burden not only for the individual but also for the healthcare system ${ }^{[3]}$. Patients with low health literacy are less likely to be able to fully understand medical instructions, utilize preventive services, or manage chronic health conditions and more likely to increase hospital visits and admissions than those with adequate health literacy ${ }^{[4,5]}$. As the population with chronic illness grows and the complexity of health care multiplies, preparing health workers with the knowledge and skills to help patients with low health literacy is imperative.

The Institute of Medicine has called for professional schools to incorporate health literacy as important content in their curricula and competency assessment ${ }^{[6]}$. The American Association of Colleges of Nursing also recommends health literacy be included in baccalaureate programs ${ }^{[7]}$. Research, however, shows that nurses report the highest rate of no prior knowledge about health literacy when compared to colleagues in medicine and dentistry ${ }^{[8]}$. Literature about teaching and learning of health literacy among nursing students or about health literacy curricular development as stated by Coleman ${ }^{[9]}$ is extremely absent. There is an urgent need to educate nurses and nursing students about health literacy and to study how nurses and nursing students provide care for patients with low health literacy.

Because of its multi-factorial nature, health literacy has been viewed by some nurse educators as a concept relative to patient education. For instance, respecting languages, helping patient understand, and promoting patient engagement during patient education described by nursing students in a previous study were framed as health literacy interventions ${ }^{[10]}$. "Deficient knowledge" is a nursing diagnosis used by nursing students to initiate information support in order to increase the patient's self-efficacy, self-regulation, and self-management ${ }^{[11]}$. Other nurse educators, however, consider the following as essential knowledge and skills about health literacy: preparing the patient to navigate through the healthcare system and to interact with healthcare providers, screening the patient for low health literacy, assessing written health care materials, creating interventions to promote health literacy, and evaluating patient learning outcomes ${ }^{[12,13]}$. As nurse educators develop evidence-based health literacy curricula, more research about how students address health literacy in practice is needed in order to capture the essential but missed health literacy content.

The purpose of this study was to explore experiences of undergraduate nursing students in caring for patients with low health literacy. To illustrate clinical experiences directly related to health literacy, student participants in this study were given a definition of health literacy before they described their clinical experiences. Findings of this study will contribute to the knowledge base needed for health literacy curricular development.

\section{Methods}

\subsection{Study design}

The university institutional review board approved this study. A qualitative content analysis method ${ }^{[14]}$ was used to identify themes in narratives written by undergraduate nursing students about their clinical experiences in caring for patients with low health literacy.

\subsection{Participants and setting}

Seventy baccalaureate nursing students in an U.S. Midwestern state university were invited to participate in this study. These students were enrolled in two separate sections of a nursing research course. This nursing research course was a 
3-hour per week course for a length of 15 weeks. Qualitative and quantitative research methods (identifying problems for research, sample/sampling, data collection, data analysis and interpretation), research analysis and critique, human subject protection issues, and linking research to evidence-based nursing practice were taught in this course. One section was for students in the traditional track and it had 49 students. Another section was for the accelerated track and it had 21 second-degree students with a prior non-nursing undergraduate degree. All students were in their 6th semester of the curriculum and in addition to the nursing research course, they were taking medical-surgical II and obstetric-pediatric nursing courses with 12 hours per week spent in clinical settings. In the 5th semester, the students had completed medical/surgical I and psychiatric-mental health nursing courses and in the 3rd and 4th semesters basic nursing skills and health assessment courses. These students were chosen because they already had had some clinical experiences from which they could use to write about the health literacy experience. Also, exposure to research in the research course might encourage them to participate in this study.

During the qualitative research lecture, students participated in a hands-on qualitative research learning activity. They acted as a study participant as well as a qualitative researcher. Being a study participant, each student spent 30 minutes writing a one-page (letter size) story about their experiences in caring for a patient with low health literacy. In small groups, students then shared their stories and worked as if they were a qualitative researcher by individually analyzing stories written by peers and discussing their findings with each other in a group. This learning activity was to expose students to qualitative data analysis. Student ability to analyze peer stories was not graded. Their analysis results were not included in this study. Students who agreed to be in this study submitted their stories at the end of the class to a box before they left the class. Study participation was voluntary.

Students were given the definition of health literacy as "the degree to which individuals have the capacity to obtain, process, and understand basic health information and services needed to make appropriate health decisions" ${ }^{[1]}$. They were asked to relate a clinical situation where the patient had difficulty finding, processing or understanding medical or health information and where they believed they had made a difference in the life of the patient by increasing the patient's health literacy. Several probing questions were provided to help students express their thoughts and feelings about the clinical event, such as where they were, what they were doing, what other people were doing, how they felt when the event started, and how they felt about the outcome of the event. These questions were broad enough to encourage students to write as much and as diverse as they could about their experiences than narrower questions, such as how do you assess the patient's health literacy or how do you help your patients understand medical instructions.

Students were told to not worry about grammar and sentence structure but to do their best in "telling" their stories. No grades were given to this writing activity nor did students write their names or any identifiable information on the papers that described their stories. To ensure that no personal demographic information could correspond individually with stories, demographic information was collected as an aggregate from course enrollment data.

\subsection{Data analysis}

Five students in the traditional track did not submit their stories. Of the 65 submitted stories, about 91\% (59 stories) described explicitly a clinical situation relevant to the definition of health literacy (finding, processing or understanding medical or health information). The research team excluded 6 stories (5 in the traditional track and 1 in the accelerated track) from analysis because these stories described what students did to increase patient physical comfort or prevent physical complications (e.g., placing an N-G tube to relieve a distended abdomen, providing mouth care to treat dry lips) and the stories did not include explicit explanation about finding, processing, or understanding of medical or health information of a patient. They were judged by the research team unanimously as irrelevant to the research project definition of health literacy. The final analysis was based on 59 stories. Morse ${ }^{[15]}$ stated that a sample size of at least 30-60 is required to obtain the richness of data when using semistructured interviews. With the sampling units of 59 stories, information redundancy was reached and codes and themes abstracted from the stories were mutually exclusive. 
Data analysis was performed by all members of the research team. Analysis involved three phases: immersing in data, open coding, and creating themes ${ }^{[16]}$. Each team member began data analysis by individually reading each story several times. During open coding, each member individually assigned a code (few words or a short sentence) to capture key thoughts in the story. Reading and coding were repeated until all aspects of the story content were coded. In the creating themes phase, research team members met to compare codes and to group codes connoting similar health literacy features into themes.

\subsection{Trustworthiness}

Measures were taken to ensure credibility, transferability, dependability, and conformability of the study ${ }^{[17]}$. To increase credibility, the research team comprised three members with expertise in health literacy, qualitative research, and nursing education. Data were analyzed by research team members individually first and validated again as a group. A detailed description of the study participant, the setting and the procedure was used to enhance transferability (applicability of study findings to other populations or settings). Dependability refers to how others can follow researchers from data analysis to conclusion. Measures to ensure dependability included using tables to demonstrate links between codes and themes and quoting excerpts from the stories when describing results ${ }^{[16,18]}$. Conformability reflects freedom from bias. Strategies used in this study to increase conformability involved using a protocol when analyzing data to ensure consistency and peer debriefing as suggested by Hsieh and Shannon ${ }^{[14]}$ to resolve differences in coding and theme generation.

\section{Results}

Of the 70 students, 62 were females and 8 were males ( 3 in the traditional track and 5 in the accelerated track). There were 61 whites, 7 blacks/African Americans (6 in the traditional track and 1 in the accelerated track), and 2 Asians (all in the traditional track). Five students whose primary language was not English were in the traditional track. The mean ages were 25 and 29 years old for students in the traditional and the accelerated tracks, respectively. Due to the anonymous nature of the study, demographic information was collected from course enrollment data, not directly from the students. No demographic data, therefore, could be identified for the 59 students whose stories were included in the final analysis.

Three themes were abstracted from the written stories. Experiences described by students in the traditional track and by those in the accelerated track were not different.

\subsection{Sensing low health literacy by behavioral cues}

The first theme summarized behavioral cues used by students to identify patients or family members with low health literacy (see Table 1) and subsequently to provide them with information or teaching. Behavioral cues included noncompliance with disease management, knowledge deficits about medical procedures, anxiety/concerns about the unfamiliar, and language barriers. Noncompliance behaviors were demonstrated by the patient's poor knowledge about self-care management of chronic diseases and lifestyle modifications. For instance, one student stated that a patient with diabetes and hypertension for years "denied using glucose or BP-controlling meds and admitted to not monitoring either" and another student described a patient "got angry because he was not pleased with the heart healthy meal he was receiving. He wanted bacon." Students also sensed low health literacy when a patient did not understand the reason why he/she needed a medical procedure that was either a diagnostic test (e.g., lumbar puncture) or a medical protocol (e.g., post-op ambulation, JP drainage) to facilitate recovery. Low health literacy was also observed when a patient or a family had anxiety and concerns about an unfamiliar medical treatment or a disease process. As described by one student, "He [baby] had a lot of mucous and secretions and was placed on an NG tube to prevent aspiration. Mom and dad were both at the bedside and this was their first baby so they were very anxious." A language barrier was another cue, triggering a student's action to provide health information for the patient. When patients did not read or speak English, students perceived them as being likely to have difficulty understanding medical information. 
Table 1. Sensing Low Health Literacy by Behavioral Clues

\begin{abstract}
Representative quotes from students
A-5: Lab revealed that he was diabetic and hypertensive, and both blood sugar and pressure were uncontrolled. When asked about medications, patient denied using glucose or BP-controlling meds and admitted to not monitoring either. Patient also disclosed that both diagnoses (DM and HTN) had been given to him years prior, but stated he decided not to follow treatment because he "felt fine."

A-18: He told us that upon his diagnosis, the care provider he was seeing provided him a book to read about. However, the pt [patient] didn't read the book or understand much of it. At that point it was obvious this man needed more pt education about his diagnosis (he was previously referred to as a "non-compliant" diabetic).

T-5: When it came time to give him breakfast, my patient got angry because he was not pleased with the "heart healthy" meal he was receiving. He kept telling my partner and I [me] that he wanted bacon. When lunch time came, we ran into a similar situation where our patient was not happy with his lunch. My partner and I finally figured out that the patient was not aware of his diet.

A-17: Upon talking with patient, I discovered why he was noncompliant. He lacked the knowledge and education about his disease. When diagnosed he was told several things and then walked out. Over the past few years he has been considered "noncompliant" because he didn't understand the lifestyle modifications that he needed to do.

A-19: The doctors entered her room and told her they needed to do a lumbar puncture. "What?" she exclaimed. "What's wrong with my spine?" She had trouble knowing their explanation and difficulty focusing.

T-10: The patient expressed that she did not like laying on her side and wished to lay flat. The nurse said okay, give it 15 more minutes and we will lay you on your back and left the room. I stayed around to teach the patient why not to lay on her back and the purpose of rotating positions.
\end{abstract}

T41: The patient I was assigned to refused to get up all day. This patient had surgery before and the doctors wanted him to ambulate that day. They had tried to wean him off his $\mathrm{O}_{2}$, but could not because the patient was not able to keep his $\mathrm{O}_{2}$ sats [saturation] up. I made it my goal for that night to educate the patient on the importance of getting up and also use his incentive spirometer.

T-45: She was being discharged home with 2 JP drains. She was given brief instructions \& given a pamphlet with/written instructions. When asked if understood she nodded her head \& the nurse left. I would tell she didn't fully understand \& seemed overwhelmed \& confused. So I asked if she was able to read the pamphlet. She smiled and \& said no.

A-6: The husband was very concerned. ...had no idea of what the doctor was talking about. I saw the worry in the husband.

T-17: The patient was very anxious about the procedure [G-tube placement] and still wasn't really sure what was going on during the procedure or what she would feel like during.

T-33: She was getting scared because no one was telling her what was wrong, so she asked me because she was younger and related better to me.

T-37: He had a lot of mucous and secretions and was placed on an NG tube to prevent aspiration. Mom and dad were both at the bedside and this was their first baby so they were very anxious. However, they were good at asking questions and wanted to learn anything.

A-13: He was not educated about how to select different food choices for a diabetic diet. He and his wife did not know English well so there was language barrier.

T-28: The mother spoke/understood some English, but not much; while the husband neither spoke nor understood. The only other time the mother had been involved with health care in the US was for the birth of her $1^{\text {st }}$ child.

\section{Codes}

Noncompliance with disease

management

Knowledge deficits about medical procedures

Anxiety and concerns about the unfamiliar

Language barriers

A: accelerated track

T: traditional track 


\subsection{Promoting health literacy with multiple strategies}

The second theme reflected interventions performed by students to help patients or family members understand and use health information and optimally to increase their health literacy (see Table 2). Intervention strategies included simplifying information, reinforcing information, giving written information, using demonstration and teach-back, adopting additional communication strategies, and collaborating with experts. Simplifying information by breaking it down into smaller units and using easy-to-understand terms was mentioned by many students. For instance, one student wrote, "I chose to intervene and help break down what the nurses, respiratory therapists, doctors and physical therapists were trying to explain. They were using medical terminology and abbreviations that he [patient] did not understand." Students also tried to ensure patient understanding by reinforcing information that had been given to the patient by other health care professionals, in particular, when the information was initially given too fast that the patient did not have enough time to process what he/she was told. Other times, students reinforced information by reminding the patient of the importance of follow-up care. Giving patients written health information such as educational pamphlets or books was a common intervention by students. Written information was often used as an adjunct method to enforce verbal instruction. When the health information was about a self-care skill such as medication injection or emptying wound drainage, students used demonstration and teach-back to show patients how to perform the skill and to watch how well they did the skill. One student stated, "After thoroughly showing him all the steps, we had him start by putting on gloves and performing the injection. He did so great and we gave him lots of praise." A few students also mentioned encouraging patients to use additional communication strategies, such as writing down questions in a log, so the patient would not forget what to ask the doctors. Many students collaborated with nurses, doctors, diabetic educators, respiratory therapists, and lactation specialists in order to give the most accurate information to the patient and to compensate for their novice role and lack of experience in practice.

Table 2. Promoting Health Literacy with Multiple Strategies

Representative quotes from students
A-6: I just had to put the drs [doctor's] words into words the pt's [patient's] husband could
understand as well as provide extra detail.
A-9: The daughter thanked me for putting it in terms her mother could understand.
A-11: I explained high blood pressure, insulin, comas, kidney disease in simple terms.
T-14: I chose to intervene and help breakdown what the nurses, respiratory therapists,
doctors and physical therapists were trying to explain. They were using medical
terminology and abbreviations that he did not understand.

T-25: The nurse and I comforted her, explained the upcoming events in short, simple ways, and brought anything she needed....The mom was so overwhelmed at the medical information thrown at her.

A-19: I stayed with her after the doctors left and helped her get repositioned with several pillows. I told her that I would go over what the doctors had reported.

Codes

Simplifying information

A-2: The doctors spoke really quickly at the patient and his wife in his thick Indian accent. The room still and the family hung on every word of boisterous medical jargon. When asked if they had questions, they responded “no" with their eyes screaming I don't understand. After he left, I asked if they had questions, and voila. They did. I was able to repeat what he had said, further explain the situation.

T-20: I explained what diabetes is, what causes it and how to manage it. I also told him that he must talk with diabetes team to get his diabetes under control (which he had declined before).

(Table 2 continued on page 81 ) 
Table 2. (Continued.)

Representative quotes from students
T-16: Not only did we explain several times what the med [medication] was for, but we
provided a pamphlet for her to take home so that she and her family could use it as a
resource.
T35: I grabbed some of the books on the unit and went to my patient's room to help him
learn.
T-38: My nurse and I got a whole bunch of education pamphlets and told her about what
side effects to expect. We also taught her about all of the medications we were going to give
before chemo to prevent some of the side effects like nausea/vomiting, conjunctivitis, etc.

T-8: After thoroughly showing him all the steps, we had him start by putting on gloves and performing the injection. He did so great and we gave him lots of praise.

\section{Codes}

Giving written information

Using demonstration and teach-back

T-15: I showed her how I was taught to wash my hands and told her to try and prevent herself from touching certain areas, such as her Indiana drain and incision.

T-29: We were patient with her. Demonstrated and watched/corrected her while she breastfed.

A-15: I informed mom that the medical staff was there to treat her client, but it was important for her to understand. I then told her to create a question log that she could use the next time the staff were in the room, expediting the question process while ensuring all questions were answered.

T-45: So I read the instructions to her slowly \& clear enough for her to understand.

A-13: The diabetic educator, nurse and myself were all able to work with the patient in different ways to help the patient understand his condition and ways that he could help manage it through his nutrition choices.

T-24: I suggested to the patient's mother to attend asthma education provided by respiratory therapy. I offered to go with her, so I could learn more and help the patient understand many confusing areas discussed in the session.

T-37: After talking to the mom and listening to how motivated she was to continue breastfeeding, I talked to her about getting in touch with a lactation consultant to ask if she could start using her breast milk for the baby's feedings.
Adopting additional communication strategies

Collaborating with experts

A: accelerated track

T: traditional track

\subsection{Closing the health information loop with positive and negative feelings}

The third theme was about the end-point outcomes regarding the clinical events. Students described two clusters of outcomes: one was related to the patient and another cluster to themselves (see Table 3). Students described positive changes in the knowledge, behaviors or emotions of their patients, such as the patient "was able to verbalize what protein was and listed several foods that were high in protein," or "had a higher capacity to understand a very basic element of her health." Students also talked about how offering information, explanation, and patient teaching relieved patient anxiety, stress, fears, and concerns. Almost all students felt positive about their interactions with patients because the patients trusted them, accepted their advice, and therefore boosted their confidence. As described by one student, "I was shocked/amazed that he had taken into consideration what I had said. Now I am not as intimidated to teach the [patient] about various topics." On the other hand, a positive feeling was also the result of feeling good about their own ability to 
identify the problem and provide necessary patient interventions. Yet, in certain situations some students experienced a sense of frustration because their patients failed to make a change. Patients who were unable to change often had a long history of smoking or a chronic disease with complications. One student described the frustration as "It seemed certain that once discharged he would immediately start smoking again." Another student had doubt about one patient's future treatment compliance because the patient "would probably continue to miss her dialysis appointments and keep coming back for health issues due to noncompliance."

Table 3. Closing the Health Information Loop with Positive and Negative feelings

\begin{tabular}{ll}
\hline Representative quotes from students & Codes \\
\hline $\begin{array}{l}\text { A-3: After our discussion, the pt [patient] was able to verbalize what protein was and listed } \\
\text { several foods that were high in protein. }\end{array}$ & $\begin{array}{l}\text { Changing patient knowledge and } \\
\text { behavior }\end{array}$
\end{tabular}

A-11: Later, a visitor offered to grab some orange juice from the fridge and the patient declined, asking for crackers and peanut crackers.

T-10: The patients now had a higher capacity to understand a very basic element of her health (how to lay down and now to make a decision/action to have favorable outcomes).

T-22: Later when I went back to check on him after he had ordered lunch, he said that he had specially chosen foods that would be more compliant with his BP [blood pressure]. He was also practicing various pain management interventions in order to keep in manageable and lower BP.

T-24: This education greatly impacted my patient's mother because she went home that evening to clean the house to remove dust and other allergens found in the house. She also learned how to properly administer her son's inhaler and clean it effectively.

A-6: Once I have the info, I shared this with the husband and was able to assure him of the treatment plan. He was very much relived from anxiety after this.

T-14: Once I explained what they were, it helped ease his fears and clam him down. Something as simple as an explanation helped this patient.

T-19: Both the patient and the family learned to support each other in the grief process and understand how their partner grieves.

T-32: She felt more comfortable with tube feedings, placing the tube herself, and the basic overall information, all the materials and resources lowered her stress and she wasn't so overwhelmed.

A-3: I felt helpful and it seemed the pt [patient] trusted me. We talked for several minutes. I was glad to help and provide additional education for this pt.

A-5: I felt good that the pt's [patient's] health would be directly affected in a positive way.

A-18: I did feel glad that I was able to have a hand in figuring out the problem and helping him get the diabetes education he needed.

T-14: I felt for this patient because no one took time to listen to his questions and explain the minor details.

T-22: I was hesitant to teach b/c I was a student. I wasn't qualified enough to do this. I was shocked/amazed that he had taken into consideration what I had said. Now I am not as intimidated to teach the pt [patient] about various topics.

T-37: I was glad I got to talk to the mom because I feel like she really didn't know her options or all of the resources to her.

A-10: I felt badly that it seemed certain that once discharged he would immediately start smoking again.

A-14: My nurse said that she would probably continue to miss her dialysis appointments and keep coming back for health issues due to noncompliance. I felt and still do that the patient needs to make her health more of a priority.

A: accelerated track

T: traditional track 


\section{Discussion}

This study explored clinical experiences of undergraduate nursing students in caring for patients with low health literacy. Three major themes were abstracted from 59 stories written by students: sensing low health literacy by behavioral cues, promoting health literacy with multiple strategies, and closing the health information loop with positive and negative feelings.

Behavioral cues were used by the students in this study to identify the patient and/or family with low health literacy. Cues were signals that encouraged students to provide information support actions, ranging from giving simple explanation to conducting extensive patient education. Behavioral cues described by the students, such as noncompliance with disease management, knowledge deficits about medical procedures, and language barriers in communication, were similar to those found in a recent systematic review in which low health literacy was associated with poor knowledge of health and disease, less adherence to health behavior recommendations and disease management, and language barriers ${ }^{[19]}$. A recent Institute of Medicine report, The Future of Nursing, identifies low health literacy among English speakers and limited English proficiency to be barriers to health care services for those that will be covered through The Affordable Care $A c t{ }^{[20]}$. Being able to recognize potential situations indicative of low health literacy will enable students to be sensitive to the information needs of those with low health literacy and to develop needed interventions to help them not only comprehend health information but also navigate through the healthcare system.

Evidence was also provided in this study that the students were comfortable in using a variety of interventions to promote patient understanding and utilization of health information. Simplifying information, reinforcing information, and using demonstration and teach-back described by the students were best practices as identified by the U.S. Agency for Healthcare Research and Quality ${ }^{[21]}$ for increasing patient health literacy and in particular for helping patients with low health literacy.

Overall, written clinical events demonstrated the students' efforts to assess the patient and/or family and to use a variety of strategies to provide them with health information in order to increase their health knowledge or self-care skills and to reduce their anxiety and concerns. Behavioral cues and intervention strategies described by the students in this study are also key principles for patient education. It is, therefore, reasonable to suggest that when health literacy is included in nursing curricular it be integrated with patient education. As simple as including a case study in clinical courses may raise the students' awareness of health literacy.

Many experts believe that using established valid instruments to assess the health literacy of the patient and the readability of the patient education materials is important because assessment data enable the care provider to match verbal and printed communication to the health literacy skills of the patient ${ }^{[13,22-23]}$. None of the students in this study employed an objective tool to assess the health literacy of the patient or the patient's knowledge of a specific disease, nor did they mention assessing written patient education materials. A previous study also found that nursing students rarely used health literacy screening tools to assess the health literacy of the patient or to evaluate the reading level of written health care materials before using them for patient teaching ${ }^{[12]}$. Educators in medicine, dentistry, and pharmacy, however, have published outcomes of their efforts to teach their students the use of health literacy instruments and readability assessment tools ${ }^{[24-26]}$. Adoption of health literacy and readability assessment tools in nursing curricular, therefore, may enhance student health literacy practice. Numerous health literacy assessment tools in English or Spanish language have been developed and many of them are short and can be easily included in routine patient assessment. For instance, the Single Item Literacy Screener ${ }^{[27]}$ is used to assess general health literacy and the Newest Vital Sign ${ }^{[28]}$ for nutrition-related health literacy. Tools used to assess the reading level of written materials are also available, such as the Simple Measure of Gobbledygook or SMOG ${ }^{[29]}$ and the Suitability Assessment of Material ${ }^{[30]}$.

As described in the stories, some students were discouraged by their inability to help patients with chronic diseases to modify lifestyles or health behaviors. The frustration was partially due to the students' lack of experience as evident by 
their frequent collaboration with other experienced health professionals when giving information to patients. It was also noted that the students in this study often described their patients as passive information recipients and their interventions were to "teach" the patients but not to empower them to become an active information seeker or an active participant in self-care. Many chronic diseases would need the patient to have self-efficacy in finding information, comparing and contrasting information, weighing risks and benefits, and taking actions to solve problems. Empowering patients to become an active information seeker or an active participant in self-care is critical, but it is a high level health literacy practice ${ }^{[22]}$ that the students in this study would benefit from further training. Thus, health literacy empowerment seems to be the needed but missed component that can be incorporated in nursing curricular. Several empowerment interventions have been recommended by health literacy experts. Ask Me $3^{[31]}$ is an empowerment tool that teaches patients to ask three questions during medical encounters in order to obtain/clarify information from care providers: what is my main problem, what do I need to do, and why is it important for me to do this? Sharing decision making is another empowerment intervention ${ }^{[32]}$. Care providers can provide patients with different health options/choices and help them understand the risks and benefits of each option before a decision is made. Further, the Agency for Healthcare Research and Quality ${ }^{[21]}$ suggests the use of action plans particularly when helping patients to manage diet change or smoking cessation. An action plan is useful for patients with low health literacy because it emphasizes one step at a time to attain a larger goal.

\section{Conclusion}

This study explored experiences of undergraduate nursing students in caring for patients with low health literacy. Students in this study assessed low health literacy by identifying behavioral cues and subsequently used multiple strategies as they interacted with patients and their families to increase their health knowledge or self-care skills. Assessment and intervention methods were similar to those of patient education. However, the students did not reflect knowledge and skills relative to health literacy screening, written education material assessment, or patient empowerment. Findings of this study imply that nurse educators should be encouraged to integrate health literacy as a construct in the undergraduate curricular when introducing patient education. Nurse educators can also emphasize objective assessment of health literacy, evaluation of patient education materials, and patient empowerment in the curricular, so students have health literacy related content and opportunities for application as they advance in the pre-licensure nursing program.

\section{References}

[1] U.S. Department of Health and Human Services (USDHHS). National Action Plan to Improve Health Literacy [Internet]. 2010. Available from: http://www.health.gov/communication/hlactionplan/pdf/Health_Literacy_Action_Plan.pdf

[2] Kurtner M, Greenberg E, Jin Y, Paulsen C. The health literacy of American adults: Results from the 2003 National Assessment of Adult Literacy (NCES 2006-483). U.S. Department of Education. Washington DC: National Center for Education Statistics. 2006.

[3] Rudd RE. Improving Americans’ health literacy. N Engl J Med. 2010; 363(24): 2283-2285. PMid:21142532 http://dx.doi.org/10.1056/NEJMp1008755

[4] Rothman RL, Yin S, Nulvaney S, et al. Health literacy and quality on chronic illness care and patient safety. Pediatrics. 2009; 124: S315-S326. PMid:19861486 http://dx.doi.org/10.1542/peds.2009-1163H

[5] Howard DH, Gazmararian J, Parker P. The impact of low health literacy on the medical costs of Medicare managed care enrollees. Am J. Med. 2005; 118: 371-377. PMid:15808134 http://dx.doi.org/10.1016/j.amjmed.2005.01.010

[6] Institute of Medicine. Executive summary. Health literacy: A prescription to end confusion. 2004. http://nap.edu/catalog/10883.html

[7] American Association of Colleges of Nursing. The essentials of baccalaureate education for professional nursing practice. 2008. Available from: http://www.aacn.nche.edu/education/pdf/BaccEssentials08.pdf

[8] Jukkala A, Deupree JP, Graham S. Knowledge of limited health literacy at an academic health center. J Contin Educ Nurs. 2009; 40(7): 298-302. http://dx.doi.org/10.3928/00220124-20090623-01

[9] Coleman C. Teaching health care professionals about health literacy: A review of the literature. Nurs Outlook. 2011; 59:70-78. PMid:21402202 http://dx.doi.org/10.1016/j.outlook.2010.12.004 
[10] Scheckel M, Emery N, Nosek C. Addressing health literacy: the experiences of undergraduate nursing students. J Clin Nurs. 2010; 19: 794-802. PMid:20500323 http://dx.doi.org/10.1111/j.1365-2702.2009.02991.x

[11] Olinzock BJ, Bloom KC. Deficient knowledge. In an Evidence-Based Guide to Planning Care. Nursing Diagnosis Handbook (8 ${ }^{\text {th }}$ ed.). BJ. Ackley, GB. Ladwig, ed. St. Louis, Missouri: Mosby Elsevier. 2008, 520-524.

[12] Cormier CM, Kotrli JW. Health literacy knowledge and experiences of senior baccalaureate nursing students. J Nurs Educ. 2009; 48(5): 237-248. http://dx.doi.org/10.9999/01484834-20090416-02

[13] Cornett S. Assessing and addressing health literacy. Online J Issues Nurs [Internet]. 2009; 14(3): Manuscript 2. Available from: http://www.nursingworld.org/MainMenuCategories/ANAMarketplace/ANAPeriodicals/OJIN/TableofContents/Vol142009/No3 Sept09/Assessing-Health-Literacy-.asp

[14] Hsieh HF, Shannon SE. Three approaches to qualitative content analysis. Qual Health Res. 2005; 15(9): $1277-1288$. PMid:16204405 http://dx.doi.org/10.1177/1049732305276687

[15] Morse JM. Determining samples size. Qual Health Res. 2000; 10(1): 3-5. http://dx.doi.org/10.1177/104973200129118183

[16] Elo S, Kyngäs H. The qualitative content analysis process. J Adv Nurs. 2008; 62(1):107-115. PMid:18352969 http://dx.doi.org/10.1111/j.1365-2648.2007.04569.x

[17] Tilley DS. Qualitative research methods. In Introduction to Nursing Research (2 ${ }^{\text {nd }}$ ed.). C Boswell, S Cannon, ed. Boston: Jones and Bartlett Publisher. 2011; 193-215.

[18] Graneheim UH, Lundman B. Qualitative content analysis in nursing research: concepts, procedures and measures to achieve trustworthiness. Nurs Educ Today. 2004; 24: 105-112. PMid:14769454 http://dx.doi.org/10.1016/j.nedt.2003.10.001

[19] Agency for Healthcare Research and Quality (AHRQ). Health literacy interventions and Outcomes: An updated systematic review. Evidence Report/Technology Assessment Number 199. AHRQ Publication No. 11-E006. Rockville, MD: Agency for Healthcare Research and Quality. 2011.

[20] Institute of Medicine. The Future of Nursing: Leading Change, Advancing Health. Washington, DC: The National Academies Press. 2011, 49-54.

[21] Agency for Healthcare Research and Quality (AHRQ). Health literacy universal Precautions toolkit. AHRQ Publication No. 10-0046-EF. Rockville, MD: Agency for Healthcare Research and Quality. 2010, 20-25 \& 63-65.

[22] Egbert N, Nanna KM. Health literacy: challenges and strategies [Internet]. Online J Issues Nurs. 2009; 14(3): manuscript 1. Available from: http://www.nursingworld.org/MainMenuCategories/ANAMarketplace/ANAPeriodicals/OJIN/TableofContents/Vol142009/No3 Sept09/Health-Literacy-Challenges.aspx

[23] Smith JA, Zsohar H. Teaching health literacy in the undergraduate curriculum: beyond traditional methods. Nurse Educ Pract. 2011; 32(1): 48-50.

[24] Devraj R, Butler LM, Gupchup GV, Poirier TI. Active-learning strategies to develop health literacy knowledge and skills. Am J Pharm Educ [Internet]. 2010; 74 (8): article 137. PMid:21179248

Available from: http://www.ncbi.nlm.nih.gov/pmc/articles/PMC2987277/pdf/ajpe137.pdf http://dx.doi.org/10.5688/aj7408137

[25] Jackson RD, Coan LL, Hughes E, Eckert GJ. Instruction of health literacy into the allied dental curriculum: First steps and plans for the future. J Dent Educ. 2010; 74(3): 318-324. PMid:20203332

[26] Primack, BA, Bui T, Fertman CI. Social marketing meets health literacy: Innovative improvement of health care providers' comfort with patient interaction. Patient Educ Couns. 2007; 68: 3-9. PMid:17418522 http://dx.doi.org/10.1016/j.pec.2007.02.009

[27] Morris NS, Maclean, CD, Chew, LD, Littenberg B. The single item literacy screener: evaluation of a brief instrument to identify limited reading ability. BMC Fam Pract. 2006; 7(21):1-7. Available from: http://www.biomedcentral.com/content/pdf/1471-2296-7-21.pdf. PMid:16563164 http://dx.doi.org/10.1186/1471-2296-7-21

[28] Weiss BD, Mays MZ, Martz W, et al. Quick Assessment of Literacy in Primary Care: The Newest Vital Sign. Ann Fam Med. 2005; 3(6): 514-522. PMid:16338915 http://dx.doi.org/10.1370/afm.405

[29] McLaughlin, G. SMOG grading: A new readability formula. Journal of Reading. 1969; 12(8): 639-646.

[30] Doak, CC, Doak, LG., Root JH. Teaching patients with low literacy skills. (2nd ed.). Philadelphia: B.B. Lippincott co. 1996, 41-60.

[31] Mika VS, Wood PR, Weiss BD, Treviño L. Ask Me 3: Improving communication in a Hispanic pediatric outpatient practice. Am J Health Behav. 2007; 31(Suppl 1): S115-S121. http://dx.doi.org/10.5993/AJHB.31.s1.15

[32] von Wagner C, Steptoe A, Wolf MS, Wardle J. Health literacy and health actions: A review and a framework from health psychology. Health Educ \& Behav. 2009; 36 (5): 860-877. http://dx.doi.org/10.1177/1090198108322819 